\title{
STUDIES ON ESCHERICHIA COLI AS A CAUSE OF ACUTE DIARRHOEA IN CALCUTTA
}

\author{
D. Sen, U. Ganguly, M. R. Saha, S. K. Bhattacharya, P. Datta, D. Datta, \\ A. K. Mukherjee, R. Chakravarty and S. C. Pal
} National Institute of Cholera and Enteric Diseases, P-33 CIT Scheme XM,
Calcutta-700 010, India

\begin{abstract}
SumMary. The prevalence of different types of diarrhoea-producing Escherichia coli among 240 patients with acute diarrhoea in hospital was investigated. The 25 patients $(10 \cdot 4 \%$ of the total) from whose faeces we isolated enteropathogenic $E$. coli $($ EPEC) were all $<5$ years old but the $29(12 \cdot 1 \%)$ from whom we isolated enterotoxigenic $E$. coli (ETEC) were of various ages, most of them $>12$ years old. No enteroinvasive $E$. coli (EIEC) strains were isolated. ETEC strains that produced heat-labile toxin (LT) were encountered more often than those that produced either heat-stable toxin (ST) alone or both LT and ST. The ETEC isolates were distributed among eight different serotypes, the commonest being O148: $\mathrm{H} 28(38 \%)$. Correlations between enterotoxin production, serotype pattern and possession of colonisation factor antigens I and II were observed.
\end{abstract}

\section{INTRODUCTION}

In recent years, Escherichia coli has been recognised as one of the major causes of diarrhoeal disease, affecting both children and adults and often requiring hospitalisation (Rowe, 1979). Three types of diarrhoea-producing E. coli have been recognised - enteropathogenic (EPEC), enterotoxigenic (ETEC) and enteroinvasive (EIEC) (Merson and Black, 1981). The present study was undertaken to determine the prevalence of different types of $E$. coli among hospitalised patients with acute diarrhoea in Calcutta.

\section{MATERIALS AND METHODS}

The 240 patients admitted with diarrhoea to the Infectious Diseases Hospital, Calcutta, during the period Jan. 1982 to Apr. 1983 were included in the study. They were of all ages and both sexes, and were unselected except that only those reporting to hospital on Mondays to Saturdays in the morning were included. Patients who had already received treatment were excluded. Faecal specimens collected on admission were examined bacteriologically for enteropathogens by standard techniques (Sakazaki et al., 1971; Edwards and Ewing, 1972; Butzler and Skirrow, 1979). A sample of each faecal specimen was stored at $-30^{\circ} \mathrm{C}$, and later screened for the detection of rotavirus antigen by an enzyme-linked immunosorbent assay 
(ELISA) technique for which the methods and the reagents were kindly supplied by Dr T.H. Flewett of the Regional Virus Laboratory, Birmingham, England.

Detection of EPEC strains. Five characteristic lactose-fermenting colonies from a MacConkey Agar culture of each specimen were individually tested by slide agglutination with EPEC antisera obtained from Wellcome Reagents Limited, England.

Detection of ETEC strains. Four individual characteristic E. coli colonies and a pool of 8-10 colonies from a MacConkey Agar culture of each specimen were tested for production of heat-labile toxin (LT) in the adult rabbit ileal loop model (De and Chatterjee, 1953) and in a modified Elek (Biken) test (Honda et al., 1981). The same colonies were also screened for production of heat-stable toxin (ST) in 1-4 day old suckling mice (Dean et al., 1972). The ETEC strains so detected were subsequently tested for agglutination with two polyvalent and 13 monospecific ETEC antisera, kindly supplied by Dr B. Rowe, Director, WHO Collaborating Centre for Phage-typing and Resistance of Enterobacteria, Central Public Health Laboratory, London. They were also tested for possession of colonisation factor antigens (CFA I and II), using specific CFA I and II antisera kindly supplied by Professor J. Holmgren, Institute of Medical Microbiology, University of Goteborg, Sweden.

Detection of EIEC strains. The E. coli strains isolated were screened for enteroinvasiveness (Sereny, 1955) and were also tested by slide agglutination with EIEC antisera, kindly supplied by Professor L.R. Trabulsi, Sao Paulo, Brazil.

\section{RESULTS}

Enteropathogenic E. coli (EPEC) were detected in the faeces of $25(10.4 \%)$, and enterotoxigenic $E$. coli (ETEC) in those of $29(12 \cdot 1 \%)$ of the 240 patients investigated. No enteroinvasive $E$. coli (EIEC) strains were encountered. Frequencies of detection of other enteropathogens are shown in table I. The distribution of EPEC and ETEC in relation to the age of the patients investigated is shown in table II. All the EPEC isolates were detected in faeces of children $<5$ years old; none of them produced LT or ST. In contrast, the ETEC strains were isolated from faeces of patients whose ages ranged from 7 months to 76 years. Of the 29 ETEC isolates, $14(48 \cdot 3 \%)$ were LT-producers, $6(20 \cdot 7 \%)$ were ST-producers and the remaining $9(31 \%)$ produced both LT and ST.

The EPEC strains encountered in this study belonged to 10 different serotypes (table III) and the ETEC strains to eight others (table IV). Among the 14 LT-producing ETEC strains, 10 belonged to serotype O148:H28 whereas the

\section{TABLE I}

Frequency of detection of various enteropathogens from faeces of 240 patients with diarrhoea in hospital

\begin{tabular}{lcc}
\hline & \multicolumn{2}{c}{$\begin{array}{c}\text { Patients with } \\
\text { positive cultures }\end{array}$} \\
\cline { 2 - 3 } \multicolumn{1}{c}{ Pathogen } & Number & Percentage \\
\hline Vibrio eltor & 78 & $32 \cdot 5$ \\
ETEC & 29 & $12 \cdot 1$ \\
EPEC & 25 & $10 \cdot 4$ \\
Rotavirus & 21 & $8 \cdot 8$ \\
V. parahaemolyticus & 18 & $7 \cdot 5$ \\
Campylobacter jejuni & 16 & $6 \cdot 7$ \\
Shigella spp. & 12 & $5 \cdot 0$ \\
Salmonella spp. & 1 & $0 \cdot 4$ \\
\hline
\end{tabular}


TABLE II

Distribution of ETEC and EPEC in relation to age of patients

\begin{tabular}{|c|c|c|c|c|c|c|}
\hline \multirow{3}{*}{$\begin{array}{l}\text { Age-groups } \\
\text { (in years) }\end{array}$} & \multirow{3}{*}{$\begin{array}{c}\text { Number of } \\
\text { patients } \\
\text { investigated }\end{array}$} & \multicolumn{5}{|c|}{$\begin{array}{l}\text { Number of patients } \\
\text { whose specimens contained }\end{array}$} \\
\hline & & \multirow[b]{2}{*}{ EPEC } & \multicolumn{4}{|c|}{ ETEC } \\
\hline & & & LT & ST & LT ST & either or both \\
\hline$<1$ & 30 & 12 & 1 & 0 & 1 & 2 \\
\hline 1 & 30 & 5 & 2 & 1 & 0 & 3 \\
\hline $2-4$ & 32 & 8 & 1 & 2 & 1 & 4 \\
\hline $5-12$ & 33 & 0 & 1 & 0 & 2 & 3 \\
\hline$>12$ & 115 & 0 & 9 & 3 & 5 & 17 \\
\hline Total & 240 & 25 & 14 & 6 & 9 & 29 \\
\hline
\end{tabular}

TABLE III

Distribution of EPEC serotypes among 240 patients

\begin{tabular}{cc}
\hline EPEC serotypes & Number of isolates \\
\hline O128:K67 & 5 \\
O114:K90 & 5 \\
O125:K70 & 3 \\
O44:K74 & 3 \\
O26:K60 & 3 \\
O112:K66 & 2 \\
O18C:K77 & 1 \\
O142:K80 & 1 \\
O111:K58 & 1 \\
O86:K61 & 1 \\
Total & 25 \\
\hline
\end{tabular}

TABLE IV

Serotype distribution of ETEC strains isolated from 240 patients

\begin{tabular}{lrccc} 
& \multicolumn{4}{c}{$\begin{array}{c}\text { Number of ETEC strains } \\
\text { producing }\end{array}$} \\
\cline { 2 - 5 } \multicolumn{1}{c}{ Serotype } & LT & ST & LT+ST & either or both \\
\hline O148:H28 & 10 & 1 & 0 & $11(38 \cdot 0)^{*}$ \\
O78:H11 & 0 & 0 & 5 & $5(17 \cdot 2)$ \\
O8: K40:H9 & 4 & 0 & 0 & $4(13 \cdot 7)$ \\
O63:H12 & 0 & 2 & 0 & $2(7 \cdot 0)$ \\
O15:H & 0 & 3 & 0 & $3(10 \cdot 3)$ \\
O25:K7:H42 & 0 & 0 & 2 & $2(7 \cdot 0)$ \\
O115:H40 & 0 & 0 & 1 & $1(3 \cdot 4)$ \\
O6: $15: \mathrm{H} 16$ & 0 & 0 & 1 & $1(3 \cdot 4)$ \\
Total & 14 & 6 & 9 & $29(100 \cdot 0)$ \\
& & & &
\end{tabular}

*( ) = percentage of the 29 ETEC strains. 
TABLE V

Correlation of enterotoxin production, serotype pattern and possession of CFA I and CFA II among the 29 ETEC strains

\begin{tabular}{|c|c|c|c|c|c|}
\hline \multirow[b]{2}{*}{ Serotype } & \multicolumn{3}{|c|}{$\begin{array}{l}\text { Number of } \\
\text { strains producing }\end{array}$} & \multicolumn{2}{|c|}{$\begin{array}{l}\text { Number of } \\
\text { strains possessing }\end{array}$} \\
\hline & $\mathrm{LT}$ & ST & LT ST & CFA I & CFA II \\
\hline O148:H28 & 10 & 1 & 0 & 0 & 8 \\
\hline O78:H11 & 0 & 0 & 5 & 5 & 0 \\
\hline $\mathrm{O} 8: \mathrm{K} 40: \mathrm{H} 9$ & 4 & 0 & 0 & 0 & 4 \\
\hline $\mathrm{O} 15: \mathrm{H}^{-}$ & 0 & 3 & 0 & 0 & 0 \\
\hline O63:H12 & 0 & 2 & 0 & 2 & 0 \\
\hline $\mathrm{O} 25: \mathrm{K} 7: \mathrm{H} 42$ & 0 & 0 & 2 & 0 & 0 \\
\hline Ol15: $\mathrm{H} 40$ & 0 & 0 & 1 & 0 & 0 \\
\hline $06 \cdot \mathrm{K} 15 \cdot \mathrm{H} 16$ & 0 & 0 & 1 & 0 & 1 \\
\hline Total & 14 & 6 & 9 & 7 & 13 \\
\hline
\end{tabular}

remaining four were agglutinated with $\mathrm{O} 8: \mathrm{K} 40: \mathrm{H} 9$ monospecific ETEC antisera. The 6 ST-producing ETEC strains were distributed among three $\mathrm{O}: \mathrm{K}: \mathrm{H}$ groups- $\mathrm{O} 15: \mathrm{H}^{-}$(three strains), $\mathrm{O} 63: \mathrm{H} 12$ (two strains) and O148: $\mathrm{H} 28$ (one strain) -while those that produced both LT and ST belonged to serotypes O78:H11 (five strains), O25:K7:H42 (two strains), O115:H40 and O6:K15:H16 (one strain each).

Correlation of enterotoxin production, serotype pattern and possession of colonisation factor antigens (CFA I and II) among the ETEC isolates is shown in table V. Of the 29 isolates, CFA I was detected in seven strains, CFA II in 13 strains and neither factor in the remaining nine strains. Among the seven CFA ${ }^{+}$strains, five were producers of LT and ST belonging to serotypes O78: $\mathrm{H} 11$ and the remaining two were ST-producers belonging to serotype O63:H12. On the other hand, 8 of the 13 $\mathrm{CFA} \mathrm{II}^{+}$strains belonged to serotype $\mathrm{O} 148: \mathrm{H} 28$ (including 7 of the $10 \mathrm{LT}$-producers in this serotype), and four others belonged to serotype O8:K40:H9 (all of them LT-producers). Thus 11 of the 14 LT-producers possessed CFA II. So also did the single strain that produced LT and ST, which belonged to serotype O6:K15:H16.

\section{Discussion}

Enterotoxigenic E. coli (ETEC) were found in this study to be among the major causes of diarrhoea, coming second to Vibrio eltor; they accounted for $12 \cdot 1 \%$ of the 240 cases. LT-producing strains were the commonest ETEC encountered, followed by those producing LT and ST. This observation corroborates earlier findings in Calcutta (Ganguly et al., 1980; Sen et al., 1983) but differs from those obtained in Bangladesh, where ETEC producing both LT and ST were isolated more commonly than those producing only LT or only ST (Sack et al., 1977; Merson et al., 1979; Merson et al., 1980).

All the ETEC isolates detected in this study were serotypable and were distributed among eight $\mathrm{O}: \mathrm{K}: \mathrm{H}$ groups. Interestingly, these $\mathrm{O}: \mathrm{K}: \mathrm{H}$ combinations were among those identified by Orskov et al. (1976), Rowe, Scotland and Gross (1977) and Merson et al. (1979) in ETEC strains isolated from faeces of patients with acute diarrhoea in different countries, including Bangladesh. 
The correlations between ETEC CFA-positivity and serotype pattern found in this investigation are similar to those previously reported by Evans and Evans (1978).

An interesting feature of the present study was that ETEC strains were detected in the faeces of patients with diarrhoea of all age-groups, whereas in other countries, including Bangladesh, most of those affected by these organisms were children (Merson and Black, 1981).

During the last three decades EPEC has been recognised as an aetiological agent of epidemic outbreaks of diarrhoea amongst infants and young children (Taylor 1961). Our study reiterates the prevalence of EPEC-associated diarrhoea in children $<5$ years old.

The authors are indebted to Dr B. Rowe, Professor J. Holmgren, Professor L. R. Trabulsi and Dr T. H. Flewett for supplying the reagents indicated above. They also thank Dr B. C. Deb, Deputy Director, National Institute of Cholera and Enteric Diseases, Calcutta for his interest and advice during the course of the study.

\section{REFERENCES}

Butzler J P, Skirrow M B 1979 Campylobacter enteritis. Clinics in Gastroenterology, 8:737-765.

De S N, Chatterje D N 1953 An experimental study of the mechanism of action of Vibrio cholerae on the intestinal mucous membrane. Journal of Pathology and Bacteriology 66:559-562.

Dean A G, Ching Y C, Williams R G, Harden L B 1972 Test for Escherichia coli enterotoxin using infant mice: application in a study of diarrhoea in children in Honolulu. Journal of Infectious Diseases 125: 407-411.

Edwards P R, Ewing W H 1972 Identification of Enterobacteriaceae, 3rd Edn. Burgess Publishing Co, Minneapolis.

Evans D G, Evans D J 1978 New surface-associated heat-labile colonization factor antigen (CFA II) produced by enterotoxigenic Escherichia coli of serogroups $\mathrm{O6}$ and O8. Infection and Immunity $21: 638-647$.

Ganguly U, Sen D, Dutta P, Pal S C 1980 Enterotoxigenic Escherichia coli associated diarrhoea in children and adults at a hospital in Calcutta. Indian Journal of Medical Research $71: 498-500$.

Honda T, Taga S, Takeda Y, Miwatani T 1981 Modified Elek test for detection of heat-labile enterotoxin of enterotoxigenic Escherichia coli. Journal of Clinical Microbiology 13:1-5.

Merson M H, Black R E 1981 Enterotoxigenic Escherichia coli diarrhoea. In: Holme T, Holmgren J, Merson M H, Mollby R (eds) Acute enteric infections in children. New prospects for treatment and prevention. Elsevier/North Holland Biomedical Press, Amsterdam, pp 81-92.

Merson M H, Black R E, Gross R J, Rowe B, Huq I, Eusof A 1980 Use of antisera for identification of enterotoxigenic Escherichia coli. Lancet 2:222-224.

Merson M H, Ørskov F, Ørskov I, Sack R B, Huq I, Koster F T 1979 Relationship between enterotoxin production and serotype in enterotoxigenic Escherichia coli. Infection and Immunity 23:325-329.

Ørskov F, Ørskov I, Evans D J, Sack R B, Sack D A, Wadstrom T 1976 Special Escherichia coli serotypes among enterotoxigenic strains from diarrhoea in adults and children. Medical Microbiology and Immunology 162:73-80.

Rowe B 1979 The role of Escherichia coli in gastroenteritis. Clinics in Gastroenterology 8:625-644.

Rowe B, Scotland S M, Gross R J 1977 Enterotoxigenic Escherichia coli causing infantile enteritis in Britain. Lancet 1:90-91.

Sack D A, McLaughlin J C, Sack R B, Ørskov F, Ørskov I 1977 Enterotoxigenic Escherichia coli isolated from patients at a hospital in Dacca. Journal of Infectious Diseases 135:275-280. 
Sakazaki R, Tamura K, Prescott L M, Benzic Z, Sanyal S C, Sinha R 1971 Bacteriological examination of diarrhoeal stools in Calcutta. Indian Journal of Medical Research 59:1025-1034.

Sen D et al 1983 Aetiological studies on hospital in-patients with acute diarrhoea in Calcutta. Transactions of the Royal Society of Tropical Medicine and Hygiene 77:212-214.

Sereny B 1955 Experimental shigella keratoconjunctivitis: a preliminary report. Acta Microbiologica Academiae Scientiarum Hungaricae 2:293-296.

Taylor J 1961 Host specificity and enteropathogenicity of Escherichia coli. Journal of Applied Bacteriology 24:316-325. 